\title{
Sentidos de aula de física para o ensino médio no discurso de licenciandos
}

Dayvid Bruno Fernandes da Silva f dayvid@yahoo.com

orcid.org/0000-0003-2544-5930

Universidade Estadual de Campinas (UNICAMP), Campinas, São Paulo, Brasil

Fernanda Cátia Bozelli

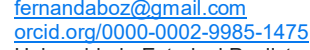

Universidade Estadual Paulista (UNESP), Ilha Solteira, São Paulo, Brasil

\section{RESUMO}

As concepções de aula de Física de docentes dessa disciplina podem ser questionáveis e, muitas vezes, dissonantes dos documentos oficiais e das pesquisas na área de Ensino de Física. Isto posto, busca-se responder à seguinte pergunta: "quais os sentidos de aula de Física para o Ensino Médio no discurso de licenciandos de uma universidade pública do estado de São Paulo?" Para responder à essa pergunta, formou-se um grupo focal constituído por licenciandos em Física, no tema Aula de Física no Ensino Médio. Registrouse o encontro em áudio e vídeo e estes registros foram posteriormente transcritos para auxiliar a análise dos discursos sob a égide do referencial de Michel Pêcheux. Os sentidos interpretados por meio da análise apontam para a concepção, por parte dos licenciandos, de que a aula de Física para o Ensino Médio deve se constituir em uma mera aplicação da Matemática. A disciplina, desse modo, não se relacionaria à vida cotidiana dos alunos e não requereria metodologias de aula que fujam do conteudismo e da memorização de equações e regras.

PALAVRAS-CHAVE: Licenciandos. Discurso. Sentidos. Aula de física. Ensino médio. 


\section{INTRODUÇÃO}

É comum haver aulas de Física no Ensino Médio que se baseiam majoritariamente em memorizações de regras, equações e leis sem haver discussões mais substanciais nessa disciplina, com professores que creem que basta conhecer conteúdos de Física para lecionar essa disciplina naquele nível de escolarização. Nessa mesma perspectiva, é assinalado pelos Parâmetros Curriculares Nacionais do Ensino Médio no Brasil (PCN)

que o ensino das ciências tem-se realizado frequentemente mediante a apresentação de conceitos, leis e fórmulas, de forma desarticulada, distanciados do mundo vivido pelos alunos e professores e não só, mas também por isso, vazios de significado. (BRASIL, 1999, p. 22).

Da mesma forma, o Currículo de Ciências da Natureza e suas Tecnologias do Estado de São Paulo (SÃO PAULO, 2012, p.15) defende a fuga da estagnação em modelos arcaicos de aula: "Hoje, mais do que nunca, as transformações tecnológicas podem atropelar o trabalho de uma escola que se cristaliza em 'modelos' estanques".

As Orientações Educacionais Complementares aos Parâmetros Curriculares Nacionais (PCN+) (BRASIL, 2002) elencam competências a serem desenvolvidas nas escolas para preparar os alunos à prática da cidadania. Entre essas competências estão a utilização de diferentes linguagens e a prática da leitura e da escrita. No âmbito da aula de Física, O PCN+ (BRASIL, 2002, p. 61, grifos nosso) traz a prerrogativa de que a Física

procura resolver problemas e prever acontecimentos, isto é, ensina-se física, no ensino médio, para preparar o aluno para lidar com situações reais de crises de energia, problemas ambientais, manuais de aparelhos, concepção de universo, exames médicos, notícias de jornal e assim por diante.

Dessa forma, é razoável dizer que, também é possível desfrutar de outras áreas do conhecimento em aulas de Física. Como a própria LDB (BRASIL, 1998) exorta, é importante utilizar-se de diferentes tipos de textos como, por exemplo, os citados manuais, exames médicos e textos jornalísticos.

É recomendado ainda que haja uma integração cultural e social nas aulas, com o objetivo de desenvolver competências e habilidades para o exercício da cidadania (BRASIL, 2002), pois a escola também deve respaldar o desenvolvimento de atitudes, valores e interesses humanistas e sociais (LEMKE, 1990; JUNIOR, 2002; LIBÂNEO, 2002). Lemke (1990) considera as ciências como linguagens conceituais específicas e, para que os alunos possam se apropriar dessas linguagens, eles precisam falar, ler e escrever utilizando conceitos científicos em diferentes contextos.

Quando o físico norte-americano Richard P. Feynman (um dos pioneiros da eletrodinâmica-quântica e prêmio Nobel de Física de 1965) visitou o Brasil na década de 1950 para lecionar no Centro Brasileiro de Pesquisas Físicas, no Rio de Janeiro, ficou surpreso com o tipo de ensino por memorização mecânica que era aplicado, em vez de raciocínio lógico. E decepcionado com a pouca relação que se faz entre a Física ensinada nas aulas e o mundo cotidiano dos alunos (JÚNIOR, 2002). Pajares (1992) e Barros (1999) apontam que, em aulas desse tipo, resta aos 
alunos decorarem fórmulas para conseguirem notas nas provas e serem aprovados ao término do ano letivo, enquanto que, as discussões em Física se tornam anêmicas. Ricardo e Freire (2007) asseveram que, dessa forma, a maior parte dos alunos termina o Ensino Médio pensando que Física e Matemática são a mesma coisa ou que Física é uma aplicação daquela outra.

Ademais, esse tipo de aula de Física pode estar ligado a aspectos referentes à formação docente (VILLANI, 1984; RICARDO; FREIRE, 2007; TARDIFF, 2010). Villani (1984) alerta sobre o escamoteamento que a Física sofre desde seu berço, entre os cientistas, até chegar às salas de aula. Segundo Carvalho e Gil-Pérez (2006, p. 10), "não basta estruturar cuidadosa e fundamentadamente um currículo se o professor não receber um preparo adequado para aplicá-lo". Além disso, os mesmos autores explicam que, quando licenciandos são questionados sobre sua própria prática, eles não têm consciência de suas deficiências como docentes e apresentam falas reducionistas que "não incluem muitos conhecimentos que a pesquisa destaca como fundamentais" (CARVALHO; GIL-PÉREZ, 2006, p. 14). Os mesmos autores citam Briscoe (1991, p. 10), expondo que há

\begin{abstract}
aspectos mais raramente levados em consideração, embora [...] essenciais: o conhecimento das concepções espontâneas dos docentes (cujo papel na formação do professor é tanto ou mais relevante que o das concepções espontâneas dos alunos em sua aprendizagem).
\end{abstract}

Assim, uma vez que as compreensões de professores de Física em formação inicial sobre aula de Física para o ensino Médio podem ser diversas, é importante investigar como compreendem a aula de Física para o Ensino. Essas divergências se dão pois, de acordo com Pêcheux (1975, apud BRANDÃO, 2002, p. 145),

se uma palavra, expressão, proposição podem receber sentidos diferentes [...] conforme refiram a tal ou tal formação discursiva, [...] elas não têm um sentido que Ihes seria "próprio" enquanto ligado à sua literalidade, mas seu sentido se constitui em cada formação discursiva, nas relações que entretêm com outras palavras, expressões proposições da mesma formação discursiva.

Então, os sentidos (BRANDÃO, 2002; ORLANDI, 2003) de aula de Física para o Ensino Médio de licenciandos podem variar de acordo com diferentes fatores, como as suas formações iniciais, seus estágios supervisionados, as teorias educacionais às quais foram expostos, a educação básica que receberam (o que inclui os professores que tiveram), entre outros aspectos. Nessa perspectiva, Tardiff (2010) afirma que os licenciandos sofrem diversas influências desde muito antes da decisão por uma licenciatura.

Dessa forma, levantou-se o seguinte questionamento: "quais os sentidos de aula de Física para o Ensino Médio no discurso de licenciandos?" Foram então traçados alguns objetivos: i) formar grupos focais com licenciandos em Física de diferentes seriações de sua graduação; ii) investigar o discurso desses licenciandos em Física por meio de Análise de Discurso Francesa, de Michel Pêcheux e iii) analisar quais são as vozes que influenciam seus discursos; iv) contribuir, por meio dos resultados desta pesquisa, com a áreas de Linguagem no ensino de Física e de formação inicial de professores em Física.

Neste artigo, serão privilegiados os dois primeiros tópicos acima mencionados, tomando como sujeitos de pesquisa os ingressantes de uma 
licenciatura em Física de uma universidade pública do estado de São Paulo. Em próximos artigos serão trazidas análises de discursos de licenciandos de outras seriações.

\section{ALGUNS PRINCÍPIOS DA ANÁLISE DE DISCURSO FRANCESA DE MICHEL PÊCHEUX}

Uma vez que pretende-se estudar discursos, a teoria da Análise de Discurso Francesa, de Michel Pêcheux, desempenha fundamental importância. Por esse referencial teórico, entende-se a Língua além dos limites de suas regras gramaticais e sintáticas, como um produto social, histórico e cultural:

\footnotetext{
a Análise de Discurso não trabalha com a língua enquanto um sistema abstrato, mas com a língua no mundo, com maneiras de significar, com homens falando, considerando a produção de sentidos enquanto parte de suas vidas, seja enquanto sujeitos seja enquanto membros de uma determinada forma de sociedade (ORLANDI, 2003, p.16).
}

Isso quer dizer que, mais que um código para comunicar informações, a Língua é concebida como um acontecimento histórico e social. Orlandi (2003) entende o conceito de discurso como sendo a língua em funcionamento e produzindo sentidos entre sujeitos. Afirma também que nenhum discurso é fechado e autônomo, estando circunscrito em um contexto social, político e histórico específicos e sendo influenciado por outros discursos. No desenrolar de suas ideias, Pêcheux apregoa que "os processos discursivos constituem a fonte da produção dos efeitos de sentido no discurso e a língua é o lugar material em que se realizam os efeitos de sentido" (BRANDÃO, 2002, p.35). Uma vez que o processo discursivo é o alicerce da produção de sentidos, é no próprio discurso que vêm à luz os próprios sentidos, fundamentados por ideologias.

O conceito de ideologia pode ser entendido como uma forma de compreender e interagir com o meio. Além disso, a ideologia é norteadora das relações sociais e pode ser considerada um fragmento da realidade de quem fala (BRANDÃO 2002, ORLANDI 2003). Brandão (2002) explica que essa prorrogativa deixa de lado o entendimento da ideologia como uma falsificação do meio, entendendo-a como uma forma de pensar o mundo, como produção de sentidos por meio de signos e materializada no discurso.

Orlandi (2003) elucida que a ideologia se materializa no discurso, assim como o discurso se materializa na fala, apontando a importância dos conceitos de formação ideológica e formação discursiva. A mesma autora expende que, pelo processo de assujeitamento, os indivíduos são interpelados por ideologias e se tornam sujeitos, passando a ocupar, inconscientemente, seus lugares em certas formações discursivas. Nesse processo os sujeitos pensam ser donos de suas próprias ideologias, quando, na verdade, foram socialmente talhados por elas. Tais posições discursivas dialogam umas com as outras seja por confrontos, alianças ou relação de dominação. Diz-se então que essas posições ideológicas, com maneiras diferentes de interpretar o mundo e seus signos, é que de fato constituem a formação ideológica (BRANDÃO, 2002). Então, uma vez que o discurso é uma materialidade da ideologia, todo discurso será dominado pela formação ideológica. 
A formação discursiva, por sua vez, ditará aquilo que deve ou não ser dito, preservando discursos anteriores, sempre na busca de uma linha limítrofe para seu domínio discursivo. A esse movimento dá-se o nome de paráfrase e, de maneiras diferentes, se profere sempre o mesmo. Assim, a formação discursiva condiciona os ditos dos sujeitos que compreendem o mundo pelo arsenal ideológico. Todavia, é pela polissemia que esses limites se expandem e se apoderam de novos usos de ditos anteriores (BRANDÃO, 2002). É por isso que na análise de uma produção discursiva, deve-se sempre levar em conta aquilo que já está fixo, o interdiscurso, e o que está em transformação, intradiscurso.

Mas, um mesmo signo pode produzir diferentes sentidos em função do contexto no qual está significando. Orlandi (2003) explica que, este contexto é chamado de condição de produção, que compreende

\footnotetext{
fundamentalmente os sujeitos e a situação. [...] Podemos considerar as condições de produção em sentido estrito e temos as circunstâncias de enunciação: é o contexto imediato. E se as considerarmos em sentido amplo, as condições de produção incluem o contexto sócio-histórico, ideológico (ORLANDI, 2003, p. 30).
}

Esse tipo de entendimento é que deu origem à Análise de Discurso, uma vez que há diferentes formas de estudar a língua: "Na análise de discurso, procura-se compreender a língua fazendo sentido, enquanto trabalho simbólico, parte do trabalho social geral, constitutivo do homem e da sua história" (ORLANDI, 2003, p.15).

Dessa forma, a mesma palavra pode produzir diferentes sentidos em diferentes ocasiões, épocas e locais. Por seu caráter polissêmico e por ser produto social e histórico é que a língua não é considerada neutra e inocente, à medida que também sempre possui interesses dos sujeitos. Por conseguinte, há manobras discursivas que atendem a essas finalidades. Um enunciador está sempre em uma formação imaginária da qual fala em seu contexto de produção. Em outras palavras, ele sempre fala, vestindo, o que chamo aqui, máscara social: o enunciador pode falar como mãe, como pai ou filho, como estudante ou professor, como amigo, patrão ou funcionário. Os discursos dessas diferentes formações imaginárias seguirão regras específicas de acordo com suas condições de produção. Além disso, ao emitir um discurso, um enunciador pode também presumir a formação imaginária de quem o escuta e modelar o seu discurso. À vista disso, os sujeitos usam também o mecanismo de antecipação, que prevê os sentidos que seu interlocutor terá de seu discurso.

É justamente por essas manobras que, ao enunciar um determinado discurso, o sujeito, na verdade, traz sentidos implícitos abaixo da superfície textual de seu dito. Por exemplo, em uma segunda- feira de manhã, um empregado, insatisfeito com seu serviço, pode dizer, ao chegar à empresa: "Como estou animado em trabalhar aqui!". Na verdade, este dito possui um não-dito, um dizer implícito: de fato, o sujeito pode estar dizendo que está desanimado em trabalhar naquele lugar. Igualmente, os discursos estão sendo manipulados a fim de, por diversos motivos, produzirem outros sentidos. Da mesma forma, até mesmo um breve silêncio pode significar algo.

Assim, é função do analista descortinar os discursos, revelando os sentidos e ideologias por meio dos signos (que podem ser palavras), que não são 
transparentes em sua forma de significar. É justamente por tais prerrogativas da Análise de Discurso Francesa de Michel Pêcheux, que essa teoria foi escolhida para essa pesquisa, pois a medida que, por meio da fala pode-se chegar ao discurso, aos sentidos produzidos por sujeitos discursivos, essa teoria também pode beneficiar os interesses desse trabalho investigativo.

\section{METODOLOGIA}

Esta investigação baseou-se em uma metodologia qualitativa de pesquisa (BOGDAN; BIKLEN, 1994; FLICK, 2002). Uma vez que esse trabalho ainda está em andamento, foram selecionados ingressantes de um curso de licenciatura em Física de uma universidade estadual paulista, pois ainda possuíam pouco contato com os discursos da área de Ensino de Física, quando comparados a outras seriações do mesmo curso. O convite aos licenciandos ocorreu de maneira presencial em sala de aula pelo primeiro autor desse artigo. Sete alunos se voluntariaram para participarem da pesquisa. Nessa mesma oportunidade, foram anotados os nomes e contatos de celular dos voluntários, que foram congregados em um grupo em aplicativo de celular de mensagens instantâneas para futuras informações sobre a pesquisa. Na oportunidade do convite, o pesquisador apresentou aos alunos, de maneira superficial, o tema, a metodologia de constituição de dados e a importância da pesquisa para o Ensino de Física e formação de professores.

O método de constituição de dados escolhido foi o de grupo focal (GATTI, 2005) e o moderador do grupo foi o primeiro autor deste artigo. É importante ressaltar que o moderador teve o papel de propiciar aos participantes uma oportunidade de debate sobre o tema aula de Física no Ensino Médio, respeitando sempre o princípio da não-diretividade, não apresentando opiniões próprias durante as discussões (GATTI, 2005). O grupo focal foi registrado em áudio e vídeo no objetivo de ampliar as oportunidades de análise.

Dessa forma, utilizando um aplicativo de mensagens para célula, junto aos participantes, uma data e um horário foram escolhidos para o encontro, que ocorreu em uma sala de reuniões na própria universidade. O grupo focal durou aproximadamente duas horas e aconteceu em um horário noturno em que os participantes não estavam em aula. No intuito de preservar suas identidades, estes licenciandos receberam aqui nomes fictícios, que estão dispostos na Tabela 1. As informações dessa tabela se relacionam com o esquema da Figura 1 que, por sua vez, apresenta a organização da sala na qual ocorreu o encontro. 
Figura 1 - Esquema de organização da Sala onde ocorreu o grupo focal.

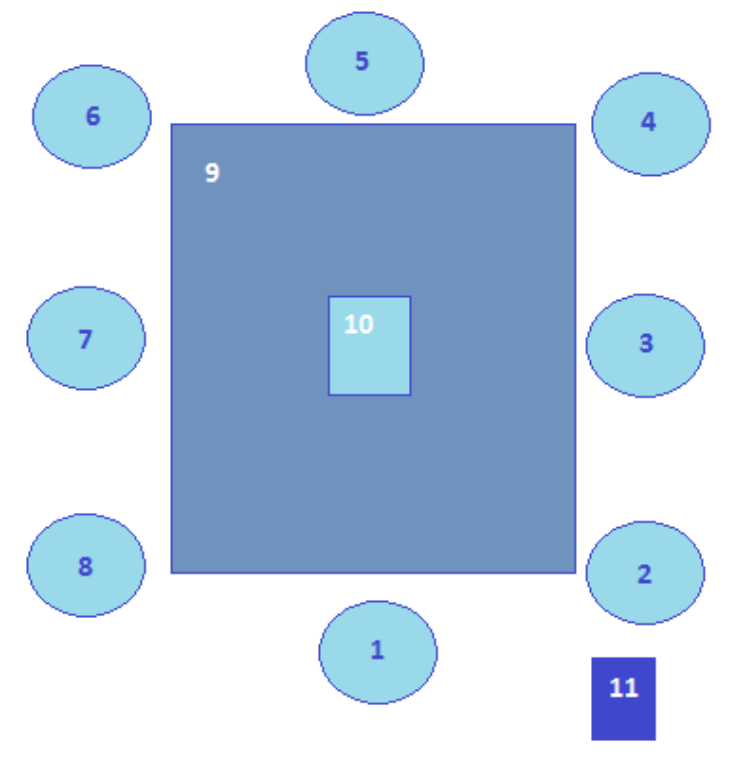

Fonte: Autoria própria (2017).

Quadro 1 - Indicadores do esquema da Figura 1 e nomenclaturas correspondentes.

\begin{tabular}{|c|c|}
\hline $\begin{array}{c}\text { Indicador no Esquema da } \\
\text { Figura 1 }\end{array}$ & Nomenclatura \\
\hline 1 & Moderador \\
\hline 2 & Vênus \\
\hline 3 & Baco \\
\hline 4 & Minerva \\
\hline 5 & Mercúrio \\
\hline 6 & Marte \\
\hline 7 & Vulcano \\
\hline 8 & Juno \\
\hline 9 & Mesa \\
\hline 10 & Gravador de áudio \\
\hline 11 & Câmera filmadora \\
\hline
\end{tabular}

Fonte: Autoria própria (2017).

No início do encontro do grupo focal, o moderador se apresentou e pediu que os participantes fizessem o mesmo. Em seguida, foi explicado novamente aos presentes, de modo superficial, os objetivos da pesquisa e alguns princípios básicos do funcionamento do grupo focal. O moderador apresentou aos participantes, por meio de um laptop, um vídeo do Porta dos Fundos ${ }^{1}$. O vídeo exibe de maneira cômica uma aula matematizada, indicando diversas problemáticas que podem 
estar presentes em aulas do Ensino Médio, inclusive nas de Física. Com o vídeo assistido nessa atividade inicial como aquecimento das discussões, os licenciandos iniciaram os debates.

A seguir, outra atividade foi desenvolvida. Folhas em branco foram entregues para que os participantes escrevessem declarações sobre aula de Física do Ensino Médio e essas folhas foram redistribuídas de maneira aleatórias para que debatessem entre si os seus conteúdos. Ao mesmo tempo em que os participantes debatiam tais declarações, algumas questões de um roteiro, previamente preparado, foram sendo sugeridas pelo moderador, ao passo que outras questões do mesmo roteiro foram espontaneamente discutidas pelo grupo, não havendo a necessidade de serem apresentadas pelo moderador. 0 roteiro de tópicos abordados está disposto no Quadro 2.

Quadro 2 - Roteiro de tópicos de discussões abordado no grupo focal.

\begin{tabular}{|c|}
\hline Tópicos para discussão no grupo focal \\
\hline Por que você escolheu cursar licenciatura em Física? \\
\hline Fale sobre suas aulas no Ensino Médio. \\
\hline Fale sobre as aulas que mais chamaram a sua atenção. \\
\hline Como eram suas aulas de Física no Ensino Médio? \\
\hline Fale sobre as aulas de Física que mais chamaram sua atenção. \\
\hline Fale dos professores com os quais você teve aula de Física. \\
\hline $\begin{array}{c}\text { Em relação às aulas de Física que você teve no Ensino Médio, agora que é um } \\
\text { licenciando em Física, como você olha para aquelas aulas de Física que você teve no } \\
\text { Ensino Médio? } \\
\text { Levando em consideração o seu percurso de aulas de Física no Ensino Médio, o que } \\
\text { você pode falar sobre Física? Como poderia falar da relação entre Física e aulas de } \\
\text { Física? }\end{array}$ \\
\hline
\end{tabular}

Fonte: Autoria própria (2017).

Logo após à realização do grupo focal, que se resumiu em um encontro, as gravações de áudio e vídeo foram transcritas para auxiliar no processo de análise, que seguiu os princípios da teoria da Análise de Discurso Francesa de Michel Pêcheux (BRANDÃO, 2002; ORLANDI, 2003).

\section{A ANÁLISE DOS DISCURSOS}

Nessa seção são apresentados aspectos da teoria da Análise de Discurso de linha francesa que respalda esse trabalho em termos de interpretação de dados, bem como a própria interpretação dos discursos.

A fim de compreender os sentidos de aula de Física do Ensino Médio dos discursos de licenciandos, analisou-se alguns episódios do grupo focal realizado. As transcrições dos registros formam o corpus bruto; mas foram selecionados recortes, as unidades de sentido, que compõem o corpus de análise (ORLANDI, 2003). De acordo com Orlandi (2003), o ato de interpretação se inicia já na seleção dessas unidades e, além disso, 
O texto não é definido pela sua extensão: ele pode ter desde uma só letra até muitas frases, enunciados, páginas etc. Uma letra "O", escrita em uma porta, ao lado de outra com a letra " $A$ ", indicando-nos os banheiros masculino e feminino, é um texto, pois é uma unidade de sentido naquela situação. [...] Portanto, não é a extensão que delimita o que é um texto (Ibid. p. 69).

A mesma autora explica que, uma vez que se busca a extensão vertical dos textos, a análise é feita nas possibilidades de interpretação nas unidades de sentidos, nas suas formações discursivas e ideológicas, no funcionamento de seus sentidos e não na extensão horizontal do texto. Ainda, esse processo de seleção de unidades de sentido é feito quando, em uma primeira leitura, o analista identifica, no corpus bruto, pistas do discurso que investiga, baseado em seus referenciais e interesses.

As análises são divididas em três partes (ORLANDI, 2003):

a) na de-superficialização, o analista define as condições de produção de cada unidade de sentido, já identificando traços do discurso sendo investigado;

b) chega-se no objeto discursivo e são feitas relações com outras formações discursivas, buscando desfazer os efeitos de ilusão da autonomia do enunciador, mostrando que o discurso naquela condição de produção é parafraseado em outras condições;

c) na análise da discursividade chega-se à formação ideológica do discurso, onde é possibilitada a compreensão dos sentidos nos discursos.

\section{A INTERPRETAÇÃO DOS DISCURSOS}

A primeira unidade de análise é proveniente de um episódio do grupo focal em que um dos participantes estava debatendo sobre como um professor de Física deveria ministrar sua aula no Ensino Médio:

Marte: [...] a ideia que eu acho, que o professor é assim, que eu tenho, a concepção que eu tenho, que se eu fosse pro Ensino Médio, sou que nem os meus, chegar e dar o conteúdo, sem ficar (pausa) de (pausa) meios termos, chegar e dar o conteúdo, ficar (prolongamento da pronúncia da última palavra em procura de complementos, mas sem conclusão). Aí é responsabilidade da galera. Por exemplo, se tem dúvida, pergunta. Se quer saber mais, corre atrás. Se não quer nada, fica quieto. "Saca"? Eu acho que, é, não é isso que acontece, obviamente, mas eu acho que isso que é, que é ser um professor coerente com (pausa) a realidade, "saca"? "Cê" passa o que "cê" tem que passar, o que "cê" tem programado "pra" passar e, as outras coisas são externas.

Marte, com um pouco de insegurança (pelo seu tom de voz), ressalta que, o que está dizendo é baseado em suas convicções: “[...] a ideia que eu acho, que o professor é assim, que eu tenho, a concepção que eu tenho, que se eu fosse pro Ensino Médio, sou que nem os meus [...]". Essa reafirmação pode indicar que ele não está seguro do que está dizendo e que prevê, por meio do mecanismo de antecipação, que outras pessoas presentes talvez não concordem com ele. Assim, Marte deixa claro que seus sentidos de aula são espelhados nos seus professores. Este discurso é prerrogativa de outros docentes que já lecionam, pois como Tardiff 
(2010) explica, um licenciando tem bastante contato com aulas antes mesmo de escolher a profissão docente e antes de lecionar de fato, assim, adquirindo conceitos, sentidos de como as aulas devem ser, espelhando-se nos seus antigos e atuais mestres.

O aluno continua: "[...] sou que nem os meus, chegar e dar o conteúdo, sem ficar (pausa) de (pausa) meios termos, chegar e dar o conteúdo, ficar (extensão da palavra em procura de complementos, mas sem conclusão). Aí é responsabilidade da galera. Por exemplo, se tem dúvida, pergunta. Se quer saber mais, corre atrás. Se não quer nada, fica quieto [...]". Marte faz duas pausas nessa unidade. Pelo tom de sua voz e olhar pensativo, ele aparenta ponderar suas palavras, talvez ajuizando sobre a formação imaginária que ele assumiu para seus ouvintes e, também, antecipando os sentidos produzidos, pensando pensar que as palavras que usaria pudessem ser inadequadas ou não concordantes com o que pensam os outros participantes. Todavia, pelo seu tom de voz, Marte aparenta crer fielmente no que está afirmando: que não ficaria de "meios termos" em aulas que ministrasse. Ele defende que, para ensinar Física, basta conhecer o conteúdo, que aula de Física deve ser baseada em acúmulo e memorização de conteúdos. Juntamente com as falas que trouxe nessa unidade, Marte demonstra crer que a responsabilidade do professor é a de, apenas, passar o conteúdo. Pode estar indicando também que, o professor de Física não tem responsabilidade sobre a aprendizagem dos alunos.

Essa também é a formação discursiva de professores do século passado (JÚNIOR, 2002) e deste, que possuem uma visão mais tradicional de suas aulas, enfatizam os conteúdos científicos (TSAI, 2002) e outorgam a maior parte da responsabilidade do aprendizado aos próprios alunos (CORTELA, 2004, apud BOZELLI, 2005). Essa ideologia que se arrasta pela história é condenada pelos PCN (BRASIL, 1999), que investem contra aulas que resumem a aula de Física à memorização de leis, regras e fórmulas e que não concordam com a realidade dos alunos (LEMKE, 1990), não atuam em favor da formação para a cidadania e que, consequentemente, não atraem a atenção dos mesmos (BRASIL, 1999), regredindo a aula para o nível da memorização para provas (BARROS, 1999).

A formação ideológica, nesse discurso, deslegitima qualquer metodologia de aula de Física que fuja do tradicionalismo, como, por exemplo, debates, que, para esse licenciando, são aulas de Física não genuínas. Lemke (1990) alerta sobre estes tipos de aula que não desenvolvem debates, discussões, escritas, leituras, experimentos e diversas outras atividades em metodologias nas quais os alunos podem realmente falar, utilizar e aprender o discurso da Física. Além disso, esses sentidos de aula de Física não dialogam de maneira positiva com as PCN+ (BRASIL, 2002), pois não apresentam a Física como construção cultural, social, econômica, histórica e política.

O licenciando em questão termina esse trecho reafirmando: “'Cê' passa o que 'cê' tem que passar, o que 'cê' tem programado 'pra' passar e, as outras coisas são externas". Essa unidade pode apontar novamente que, para ele, a aula de Física deve evitar metodologias diferenciadas e inovadoras. Esse discurso é semelhante ao de professores de Física que possuem poucas horas semanais, por turma, para lecionarem, necessitando preencher suas aulas com o máximo possível de conteúdos para poderem cumprir com as exigências relacionadas ao conteúdo programático. Além disso, esse também é o mesmo discurso de professores que baseiam suas aulas na necessidade de preparar seus alunos para os vestibulares e 
outros tipos de avaliações de larga escala (PEREIRA et al., 2007). Essas formações discursivas apontam para uma ideologia que considera que as aulas de Física são um produto necessário para se adentrar nas universidades (TARDIFF, 2010) e não um promotor de formação para a cidadania (JÚNIOR, 2002; BRASIL, 2002; SÃO PAULO, 2012). Somando-se a isso, esse discurso denota como as avaliações de larga escala e de classificação afetam as aulas de Física.

Quando Marte diz que "as outras coisas são externas", está isolando a Física de todo contexto social dos alunos (BRASIL, 2002). É o discurso que é produzido por muitos docentes no ensino de ciências nas escolas (LEMKE, 1990). Esse tipo de aula de Física se fundamenta em uma concepção de Ciência neutra e isolada das subjetividades humanas, uma Ciência produzida por homens brancos e de classe média alta, uma Ciência mística e exotérica. A Física presente nesses tipos de aula somente é possível ser compreendida pelos superdotados de inteligência (ALLCHIN, 2004; LEMKE, 1990). Nessa ideologia, na aula de Física, o professor apenas apresenta fatos incontestáveis da natureza, como se o cientista buscasse no mundo informações prontas e acabadas, de forma semelhantemente a um fotógrafo (BRONOSWKI, 1979), não permitindo assim, metodologias de aulas não tradicionais.

Ao que apresentou Marte na unidade de análise anterior, o diálogo continuou:

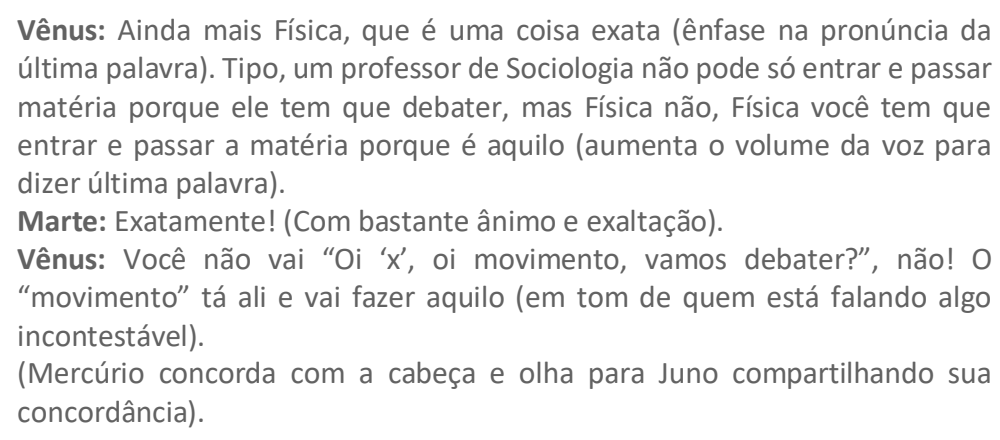

No início desta unidade, Vênus compara duas disciplinas: Sociologia e Física. Essa aluna caracteriza a Física como uma ciência exata, apresentando indícios de como deve ser a respectiva aula. O mesmo discurso está presente na compreensão de alunos e professores em disciplinas científicas, devido aos seus sentidos de Física e, consequentemente, de aula de Física (TSAI, 2002; LEMKE, 1990). Os sentidos que os licenciandos têm de Física ditam como devem ser aulas de Física, incluindo metodologias, materiais didáticos e temas. Assim, o uso de narrativas, diálogos, filmes, teatros, ficções científicas, poesias, histórias em quadrinhos, grupos de debate e discussão estão descartados. Lemke (1990) critica esses sentidos de aulas de disciplinas científicas, dizendo que as mesmas levam à uma alienação dos alunos sobre Ciência e sobre aulas de conteúdos científicos (aqui a Física), que a elevam a um patamar de superioridade, objetividade e abstração que foge das experiências humanas cotidianas.

Marte continua a discussão:

Marte: [...] que nem você falou (se referindo à Vênus), na, na sociologia, cara, isso é essencial [...] porque é uma questão social, saca? Vênus: Sim.

Marte: $E$, independendo do, da "maté..." (pausa para organizar a fala), do tópico da matéria que ele tá passando, ele tem que saber que "cê" "tá" 
interagindo certo com o aluno, "sacou"? Porque isso é muita interpretação, ainda mais em Filosofia e Sociologia, cara.

Este licenciando concorda com Vênus e diz que, no Ensino Médio, em disciplinas como Filosofia e Sociologia é possível elaborar discussões e grupos de debate, pois as próprias disciplinas são de natureza social. É feita uma comparação entre diferentes metodologias de aula: para Sociologia e Filosofia e para Física. Segundo Marte, os alunos podem trazer suas opiniões nessas aulas. Também existe um não dito no dito do participante: ao mesmo tempo que diz que em Sociologia e Filosofia essas metodologias são permitidas, ele aparenta estar compreendendo que a disciplina de Física não é de cunho social, não engloba a vida cotidiana dos alunos, a política, a economia, a sociedade e a cultura. Esse discurso traz o sentido de que aula de Física não promove uma disciplina que faz parte da cultura e por isso não deve ser debatida: se a Física está fora da realidade dos alunos, foge de seu escopo de argumentação. Esse discurso entende essa ciência como uma verdade que deve ser aceita, reproduzida e não contestada (BRONOWSKI, 1979), não sendo permitidas metodologias presentes em outras disciplinas (LEMKE, 1990).

Marte então se aventura a explicar que em Sociologia e Filosofia é necessário que o professor interaja com os alunos e se responsabilize pela forma como seu discurso chega aos alunos. Todavia, o licenciando fica confuso ao dizer, primeiramente, "independe da matéria" e depois corrigir sua fala para "tópico da matéria". Assim, pretexta alguma confusão entre matéria como disciplina e matéria como conteúdo. O licenciando parece ter demonstrado um ato falho que o levaria a uma contradição se usasse a palavra "matéria" significando "disciplina", uma vez que o discurso do mesmo traz o sentido de que algumas metodologias não são permitidas em Física, mas sim em Filosofia e Sociologia. O não dito no dito dessa unidade é que, as metodologias que exigem mais diálogo entre professores e alunos não são permitidas em aulas de Física, pois é só "chegar e dar o conteúdo, sem ficar de meios termos".

Marte reforça ainda a questão da interação do professor com o aluno: para ele, em aulas de Física não é necessário que o professor interaja com os alunos:

Marte: Eles (os professores de Física) "tavam" lá "pra" dar aula; davam aula, davam o conteúdo e (prolongamento da pronúncia da última palavra) e pronto, sabe? [...] A gente não tinha muito contato com eles. Só que eu gostava muito disso [...].

Para este licenciando, dar aulas de Física não exige que o professor interaja em discussões e debates com os alunos; pelo contrário, o professor deve controlar a fala dos alunos que, quando interagem com o professor, é para responderem perguntas e receberem uma avaliação (LEMKE, 1990).

Outro participante entra no debate em desenvolvimento:

Vulcano: [...] o que não dá "pra", tipo, "pra" entender, é por que que ele, por que eles, eles veem a Física como uma outra parte da Matemática. Eles não veem que a Física é uma "matemática filosófica", assim por dizer, entendeu?

Vulcano expressa que percebe a Física sendo considerada, por professores do Ensino Médio, como uma subdivisão da Matemática. Aqui, o licenciando faz despontar a formação imaginária que sobreviveu de seus professores de Física 
daquela seriação. Lemke (1990) e Pajares (1992) explicam que, as aulas que docentes frequentaram, durante a formação básica, continuam vivas em suas crenças. Continuando, o licenciando indica compreender que a Física é tratada nas aulas do Ensino Médio, sem meandros, como Matemática. Isto é, naquele nível escolar, não há grandes diferenças entre aula de Física e aula de Matemática. De fato, a maioria dos alunos termina o Ensino Médio não sabendo distinguir Física de Matemática (RICARDO; FREIRE, 2007) e seus sentidos apontam para uma Aula de Física que se resume em Matemática.

Como apresentado anteriormente, Vênus fez uma distinção entre as aulas de Física, de Sociologia e de Filosofia, em termos de epistemologia, pautando possibilidades metodológicas. Por sua vez, no trecho considerado, Vulcano discorda desse sentido de aula de Física tradicional e análoga às aulas de Matemática e, faz isso buscando elementos para caracterizar as aulas de Física. Ele diz que a Física é uma "matemática filosófica". Pode-se interpretar que o sentido de Física, como sendo Matemática, ainda está presente no discurso de Vulcano, e essas sãos as vozes daqueles docentes que se limitam ao teor matemático e conteudista em suas aulas de Física (LEMKE, 1990).

Contudo, como nenhum discurso é autônomo, o sentido de aula de Física no discurso de Vulcano está sendo transformado polissemicamente, uma vez que o licenciando também sopesa sobre o caráter filosófico dessa ciência. Isso pode indicar que ele está sendo interpelado por outras ideologias, agora, entendendo a Física como um produto cultural, social, político e histórico que, nas aulas, permite metodologias mais inovadoras. Esse processo polissêmico ocorre porque, ainda estando no primeiro ano de Licenciatura em Física, Vulcano traz fortemente marcas dos discursos das aulas de Física que vivenciou no Ensino Médio. Por outro lado, tendo contato com novos discursos, agora na universidade, passa a ser interpelado por analogias que consideram que a aula de Física não é apenas equações, regras e números, mas que é também filosofia, que é desenvolvida por uma comunidade com ideologias próprias, que permite discussões e debates, que é cultural, social, política (BRONOWSKI, 1979; LEMKE, 1990; BRASIL, 2002).

O debate estava sendo desenvolvido em relação à forma como a Física é tratada nas aulas do Ensino Médio e Vulcano apresentou uma contraposição em relação à Vênus e Marte. Vênus respondeu em tréplica, recebendo apoio de Mercúrio.

Mercúrio: Poderia se dizer então que, fazendo uma associação, a Matemática seria como uma linguagem de programação; e o resultado final de tudo, de toda sua codificação, o programa final seria a Física.

Vênus inicia sua explicação caracterizando a Física e utiliza predicados que julga serem da Matemática. Ela entende que a Matemática é a linguagem utilizada 
pela Física, a estrutura básica de funcionamento dessa ciência, o meio pelo qual a Física se expressa e se estrutura. Vênus traz ainda um caráter de universalização da Física, novamente, por meio da Matemática, uma vez que diz que, apesar de haver diversos idiomas, a Matemática é única. Todavia, mesmo utilizando adjetivos que julga serem da Matemática, a licencianda está se referindo à Física: busca delinear a Física por meio de uma descrição da Matemática.

Então, Vênus diz que a Física é perfeita, porque não é passível de interpretações "do vocabulário", da língua; mas quem usa a língua? Os sujeitos. Assim, a Física estaria blindada da subjetividade dos sujeitos que se expressam e interpretam, pelo discurso (que é definido como a língua em funcionamento e gerando sentidos entre sujeitos). Ao mesmo tempo, então, a licencianda exclui todas as condições de produção (históricas, sociais, políticas, econômicas, ideológicas, entre outras) que afetam diretamente no desenvolvimento de toda ciência e produto humanos.

Seguindo, no final da unidade apresentada, Vênus se exalta, aumenta o volume da voz de maneira incisiva, bate na mesa com as duas mãos e diz que Física "é aquilo e pronto", e usa novamente a Matemática como argumento. Logo em seguida, Mercúrio interrompe Vênus, e aparenta estar completando seu discurso, trazendo elementos de Ciência da Computação ${ }^{2}$. Ele faz uma analogia para ressaltar a relação entre Física e Matemática ao explicar que Física seria como um programa computacional e a Matemática seria a linguagem desse programa. Quando Mercúrio faz essa analogia, concorda com os argumentos de Vênus, considerando a Matemática o cerne existencial da Física. Assim, está sendo considerado que a Matemática é uma condição necessária para a existência da Física.

A aula de Física para o Ensino Médio defendida nesses discursos recorre à caracterização da Física por meio de uma suposta paridade entre Física e Matemática. Esse tipo de raciocínio é comum entre alunos e professores pois, a forma como se entende a ciência em questão direciona os sentidos sobre como deve ser a aula correlata (LEMKE, 1990; TSAI, 2002). Ao utilizar elementos do sentido que se tem de Matemática para explicar a Física, também pode estar sendo dito, em um não dito, que Física funciona como a Matemática, que Física é Matemática ou que é Matemática aplicada (RICARDO; FREIRE, 2002). Estes sentidos mobilizam, por conseguinte, o sentido de aula de Física.

Tendo em vista os discursos aqui analisados, estão elencados abaixo, por meio de tópicos, os sentidos desvendados nos discursos considerados neste artigo. Para os licenciandos que participaram dessa pesquisa, as aulas de Física para o Ensino Médio:

a) devem ser conteudistas, isto é, focar na apresentação do máximo de conteúdo possível, além do que, basta ao docente conhecer os conteúdos da Física para ser capaz de leciona-los;

b) se restringir à metodologias tradicionais de aula, onde o professor passa a matéria e os alunos devem estudar o conteúdo em casa para que possam aprender de fato, já que os discentes devem ser totalmente responsabilizados pelo sucesso ou fracasso de seus aprendizados; 
c) não devem abrir espaço para questões de cidadania, política, cultura e sociedade;

d) devem seguir, estrita e fidedignamente, um conteúdo programático, focando nos conteúdos, como que transferindo conhecimento;

e) são grandemente influenciadas pelas exigências dos vestibulares, que viabilizado ingresso dos alunos às universidades;

f) devem ser pautadas por metodologias que se resumem à apresentação de conteúdos aos alunos, permanecendo em modelos tradicionalistas estanques de aulas do século passado, jazendo os alunos em uma posição passiva nas aulas (copiando a matéria para estudarem em casa, sendo que somente assim podem aprender);

g) compreendem a Física como um conjunto de leis e verdades irrefutáveis;

h) não permitem o uso de narrativas, diálogos, filmes, teatros, ficções científicas, poesias, histórias em quadrinhos, grupos de debate e discussões, entre outras metodologias e materiais didáticos que fogem do tradicionalismo;

i) não possibilitam metodologias que tragam espaço para que os alunos debatam e se coloquem na aula de maneira mais ativa, pois não é possível debater os conhecimentos científicos em Física como se faz em Sociologia e Filosofia, por exemplo;

j) não exigem que o professor interaja e se envolva em discussões e debates com os alunos, pelo contrário, o professor deve controlar a fala dos alunos que, quando interagem como professor, é para responderem perguntas;

k) têm a concepção da Física como uma ciência neutra e isolada das subjetividades humanas, uma ciência distante da realidade da vida dos alunos e que apenas pode ser compreendida por pessoas dotadas de superinteligência, os cientistas;

I) não abrem espaço para debates, argumentações, discussões e posição pessoal ativa dos alunos em relação aos conteúdos estudados;

m) devem primar a memorização de leis, regras e fórmulas e exigem alto teor matemático para serem validadas, devendo se limitar à resolução de exercícios e problemas de manipulação de equações, uma vez que se compreende a Física análoga à Matemática;

n) não abrem espaço para serem trabalhadas competências e habilidades para a cidadania, como argumentação, escrita, leitura, criatividade, entre outras;

o) não considerem a Física como um produto social, histórico, político, econômico, criativo e humanístico.

Percebe-se então que, os sentidos de aula de Física presentes nas unidades de sentido apresentadas e analisadas, funcionam em um discurso que concebe uma aula de Física altamente matematizada e conteudista, sendo desenvolvidas 
Esses sentidos de aulas, por sua vez, não concebem a aula de Física como sendo uma oportunidade de desenvolver habilidades e competências para a cidadania, como recomendado por documentos oficiais (BRASIL, 1999; BRASIL, 2002; SÃO PAULO, 2012).

\section{CONCLUSÕES}

Com o intento de investigar os sentidos de aula de Física para o Ensino Médio de licenciandos de uma universidade estadual do Estado de São Paulo, partiu-se primeiramente para a investigação dos discursos de ingressantes daquela universidade. $O$ desenvolvimento da presente investigação viabilizou uma situação de debate, entre os próprios alunos, por meio do método de grupos focais, na qual os licenciandos discutiram sobre o tema proposto, isto é, aula de Física para Ensino Médio. Foi possível, por meio do processo analítico proposto, quer dizer, a teoria da Análise de Discurso Francesa, de Michel Pêcheux, estudar os discursos registrados.

Os discursos dos participantes do estudo apontam para o sentido de que não é possível ou desejável trazer metodologias diferenciadas para as aulas de Física. Isso porque a Física seria uma disciplina exata, impassível de ser argumentada e questionada. Os licenciandos demonstram alimentar a ideologia segundo a qual os conhecimentos da Física se assentam em uma verdade irrefutável, e desse modo, não haveria o que ser discutido. Assim sendo, não haveria razões para se buscar metodologias que permitam que os alunos se tornem mais ativos nas aulas de Física do Ensino Médio.

Interpretamos também sentidos de que em aulas de Física há apenas que se aceitar seus conteúdos como verdades absolutas e universais. Além disso, de acordo com esses discursos, a aula de Física deve primar pelo acúmulo de conteúdos e pela memorização de leis e fórmulas. Nesse contexto, os alunos são considerados tábulas rasas e todo seu arsenal de conhecimentos prévios e as suas potencialidades de participação ativa são ignorados.

Ressaltamos que esses tipos de aula são vazios de significado para os alunos e resultam apenas em alunos passivos que entendem a Física como mera aplicação da Matemática e que apenas memorizaram seus conteúdos para poderem ser aprovados na disciplina. Esse tipo de ensino não coincide com uma proposta que possibilite uma formação ampla e que vise a prática de habilidades e competências para a cidadania e, muito menos, para uma formação científica, pois até mesmo nesse contexto a memorização mecanizada não é adequada. Há, então, uma necessidade de aproximação entre as vidas dos alunos e a Física, no contexto da sala de aula.

Também foi possível perceber, em um dos discursos, traços de uma ressignificação acerca de sentidos de aula de Física. Essa polissemia ocorre porque, agora na licenciatura, o sujeito é interpelado por novas ideologias que compreendem a Física como um produto social, histórico, político, cultural, filosófico e humano, englobando a realidade daqueles que produzem essa ciência. Justamente por isso, a Física deixa de ser uma ciência estanque, mística e distante da realidade dos alunos. Assim, há abertura de oportunidades, nas aulas de Física, para metodologias que envolvem debates, argumentações, uso de filmes, poesias, 
histórias em quadrinhos, entre tantas outras oportunidades que viabilizam a formação para a cidadania.

Como apontamos no presente artigo, muitos alunos terminam o ensino médio com concepções equivocadas tanto sobre a natureza da Física quanto sobre aula de Física. No contexto de nossa pesquisa, os discursos dos ingressantes de um curso de licenciatura em Física ratificam essa afirmação. Dessa forma, corroboramos a importância de investigação sobre como estão sendo formados os licenciandos e como pensam a disciplina com a qual trabalharão nas salas de aula da educação básica. Assim, no âmbito do ensino em ciências, em especial Física, ansiamos que a discussão que tecemos possa gerar reflexões produtivas entre os diferentes agentes da educação básica e da formação inicial de professores. 


\title{
Meanings of physics class for high school in the discourse of teaching degree in physics' students
}

\begin{abstract}
The conceptions of the Physics class of teachers of this discipline can be questionable and, often, dissonant of the official documents and the researches in the area of Physics Teaching. Then, we aimed to answer the following question: "What are the meanings of Physics class for High School in the discourse of undergraduate students of a public university in the state of São Paulo?" To answer this question, a focus group constituted by graduates in Physics was organized on the theme Physics Class in High School. The meeting was recorded in audio and video and these records were later transcribed to assist the analysis, of the discourses, under the aegis of Michel Pêcheux's reference. The interpreted meanings point to the conception, by the undergraduate students, that the Physics class for the Secondary School must be constituted by mere applications of Mathematics. Thus, this subject would not relate to the daily life of students and would not require classroom methodologies to escape from content and memorization of equations and rules.
\end{abstract}

KEYWORDS: Undergraduate students. Discourse. Meanings. Physics class. High school. 


\section{NOTAS}

1. Porta dos Fundos é um grupo que produz vídeos cômicos e os divulgam em plataformas online, principalmente, de reprodução de vídeo. O vídeo ao qual se faz referência neste artigo pode ser acessado por meio do link https://www.youtube.com/watch?v=2vzwOeYgYUY.

2. Mercúrio já havia iniciado um curso de graduação, Ciências da Computação, antes de cursar Licenciatura em Física, tendo, todavia, mudado sua área de interesse e migrado para a atual licenciatura.

\section{REFERÊNCIAS}

ALLCHIN, D. Pseudohistory and pseudoscience. Science \& Education, v. 13, 179190, 2004.

BARROS FILHO, J. Construção de um Sistema de Avaliação em um Curso de Eletrodinâmica de Nível Médio. Dissertação (Mestrado), Faculdade de Educação, Universidade Estadual de Campinas, Campinas, 1999.

BOZELLI, F. C. Analogias e Metáforas no Ensino de Física: o discurso do professor e o discurso do aluno. 2005. 235 f.. Dissertação (Mestrado em Ensino de Ciências) - Faculdade de Ciências, Universidade Estadual Paulista de Bauru, São Paulo.

BRANDÃO, H. H. N. Introdução à Análise do Discurso. 1 ed. Campinas: Editora da Unicamp, 2002.

BRASIL. Lei de Diretrizes e Bases da Educação: Lei no 9.394/96 - 24 de dez. 1996. Estabelece as diretrizes e bases da educação nacional. Brasília, 1998.

BRASIL. Secretaria de Educação Média e Tecnologia. Parâmetros Curriculares Nacionais: ciências da natureza, matemática e suas tecnologias. Brasília: MEC/SEMTEC, 1999.

BRASIL, Ministério da Educação. Secretaria da Educação Média e Tecnológica. Orientações Educacionais Complementares aos Parâmetros Curriculares Nacionais (PCN+). Brasília: MEC, 2002.

BRONOWSKI, J. O homem e a ciência: ciência e valores humanos. São Paulo, Ed. Da Universidade de São Paulo, 1979.

CARVALHO, Anna. M. P., GIL PÉREZ, Daniel. Formação de professores de ciências: tendências e inovações. 2.ed. São Paulo: Cortez, 1995. 120 p. 
FLICK, U. Uma Introdução à pesquisa qualitativa. São Paulo: Artmed Editora, 2002.

GATTI, B. A. Grupo focal na pesquisa em ciências sociais e humanas. Brasília: Liber Livro, 2005.

JÚNIOR, G. D. C. As concepções do ensino de Física e a construção da cidadania. Caderno Catarinense de Ensino de Física, v. 19, n. 1, p. 53-66, abr. 2002.

KUSSUDA, S. R. A Escolha Profissional de Licenciados em Física de uma universidade pública. 2012. 184 f. Dissertação (Mestrado em Educação para a Ciência). Faculdade de Ciências, UNESP, Bauru, 2012.

LEMKE, J. L. Talking science: language, learning and values. Norwood, NJ: Ablex, 1990.

LIBÂNEO, J. C. Didática: velhos e novos temas. Edição do autor. 2002. Disponível em

<http://professor.pucgoias.edu.br/SiteDocente/admin/arquivosUpload/5146/ma terial/Did\%C3\%A1tica\%20-\%20\%20Velhos\%20e\%20novos\%20temas.doc>.

Acesso em: 20 de fev. de 2017.

ORLANDI, E. P. Análise de Discurso: princípios e procedimentos. 5 ed. Campinas: Pontes, 2003.

PAJARES, M. F. Teacher's beliefs and educational research: Cleaning up a messy construct. Review of Educational Reseach, v. 62, n. 3, p. 307-332, 1992.

PEREIRA, A. S.; COELHO, M.F.F.; SILVA, M. M.; COSTA, I. F.; RICARDO, E.C. Um estudo exploratório da concepção de alunos sobre Física no Ensino Médio. XVII Simpósio Nacional de Ensino de Física, 17., 2007. São Luiz - MA. Anais...

Disponível em:

http://www.sbf1.sbfisica.org.br/eventos/snef/xvii/sys/resumos/T0565-1.pdf. Acesso em 22 de mar. de 2017.

RICARDO, E. C; FREIRE, J. C. A. A concepção dos alunos sobre a física do ensino médio: um estudo exploratório. Revista Brasileira de Ensino de Física, v. 29, n. 2, p. 251-266, 2007.

SÃO PAULO (estado). Secretaria da Educação. Currículo do Estado de São Paulo 
TARDIFF, M. Saberes docentes e formação profissional. 11 ed. Petrópolis: Vozes, 2010.

SCHWARTZMAN, S. O ensino médio no Brasil é formal, acadêmico, voltado para o vestibular. Não atende jovens com outros interesses. Entrevista, Revista Ensino Superior Unicamp, v. 1, n. 2, p. 16-25, 2010.

TSAI, C. C. Nested epistemologies: Science teacher's beliefs of teaching, learning and Science. International Journal of Science Education, v. 24, n. 8, p. 771-783, 2002.

VILLANI, Alberto. Reflexões sobre o ensino de Física no Brasil: Práticas, Conteúdos e Pressupostos. Revista de Ensino de Física, v. 6, n. 2, dezembro de 1984, p. 76 95.

Recebido: 15 jan. 2017

Aprovado: 19 jul. 2018

DOI: 10.3895/actio.v3n2.7627

Como citar:

SILVA, D. B. F.; BOZELLI, F. C. Sentidos de aula de física para o ensino médio no discurso de licenciandos ACTIO, Curitiba, v. 3, n. 2, p. 133-153, mai./ago. 2018. Disponível em: <https://periodicos.utfpr.edu.br/actio>. Acesso em: XXX

Correspondência:

Dayvid Bruno Fernandes da Silva

Rua Santa Isabel, n. 1125, Barão Geraldo, Campinas, São Paulo, Brasil.

Direito autoral: Este artigo está licenciado sob os termos da Licença Creative Commons-Atribuição 4.0 Internacional. 